FACULdAdE de FormaçÃo de Professores

\title{
TRABALHANDO COM LITERATURA DE CORDEL NO ENSINO FUNDAMENTAL: RELATO DE UMA VIVÊNCIA
}

\author{
Marcella Braga Cobian (UERJ) \\ Mariana Fernandes de Lima Costa (UERJ) \\ Maria Isaura Rodrigues Pinto (UERJ) \\ $\underline{\text { m.isaura@ig.com.br }}$
}

\section{Proposta e metodologia}

O relato a ser apresentado diz respeito às atividades realizadas pelas bolsistas Marcella Braga Cobian e Mariana Fernandes de Lima Costa, na turma 702 , do $7^{\circ}$ ano, do ensino fundamental do Colégio Estadual Dr. Adino Xavier, localizado no Município de São Gonçalo, durante o desenvolvimento de uma das etapas dos projetos "Leituras da Tradição Oral e Folclórica" e "Leitura na Cordelteca da FFP", ambos coordenados pela professora Maria Isaura Rodrigues Pinto.

O desejo de ressaltar o valor da leitura de folhetos de literatura de cordel no universo da sala de aula foi o que levou à elaboração e implementação, na escola mencionada, do mini- projeto "Conhecendo o Cordel", que será agora alvo de atenção.

Apresentar a literatura de cordel, nas escolas, não é uma tarefa fácil nem tampouco recorrente. O notório preconceito que se tem em relação à literatura de cordel fica logo evidenciado no exame de materiais didáticos, visto que muitos não abordam o cordel e a minoria que o faz, muitas vezes, focaliza essa produção de forma equivocada e preconceituosa, solicitando dos alunos, como atividade, a reescritura do texto, com a correção dos "erros gramaticais", que, como se sabe, são, na verdade, variedades de registro.

Assim, não é difícil perceber que a literatura de cordel, rica expressão da poesia popular brasileira, ainda pouco valorizada, está quase ausente do ambiente escolar. Sabe-se que os fatores responsáveis por essa exclusão, em geral não-assumida, são inúmeros, dentre

eles, está o aludido preconceito linguístico. Por isso mesmo, tendo-se 
em vista um ensino democrático, julga-se relevante o trabalho com essa produção literária e o estudo de suas especificidades.

Além disso, o cordel é uma importante fonte de representação da cultura popular nordestina, constitutiva da pluralidade literária do país, cuja escritura viabiliza a abordagem de uma ampla gama de temáticas e conteúdos poético-expressivos, fatores que fazem dele um objeto de estudo versátil e valoroso.

Para uma melhor constatação do pouco, quase nulo, tratamento dado ao cordel e às suas especificidades, no contexto escolar, julgou-se interessante aplicar um questionário que aferia o conhecimento dos alunos acerca do gênero, tomando-se por base um modelo de proposta inserido no livro Acorda cordel na sala de aula (VIANA, Arievaldo Lima, 2006). O questionário continha oito questões que se dividiam entre múltipla escolha e discursiva. Através desse instrumento de sondagem, foi conferido que o número de alunos que conhecia a literatura de cordel e possuía conhecimentos sobre versificação era mesmo muito baixo, conforme demonstram os gráficos da página seguinte.

Após o exame dos dados, ficou reafirmada a necessidade de desenvolver o projeto aludido que consistia, em termos gerais, num trabalho de apresentação, de divulgação e de estudo do gênero cordel. Dentre os objetivos específicos a serem alcançados, esperava-se que o aluno fosse capaz de: verbalizar a respeito de seus conhecimentos sobre literatura de cordel; distinguir o gênero cordel de outros gêneros textuais, reconhecendo suas especificidades estruturais, temáticas e estilísticas; expressar-se oralmente através de leituras coletivas de folhetos de cordel; interpretar as poesias de cordel trabalhadas; identificar a intertextualidade do gênero cordel com outros gêneros discursivos; escrever e produzir seus próprios folhetos de cordel.

É importante frisar que, na busca de se alcançar os objetivos, houve a preocupação acentuada em se fazer conhecer, explorar e respeitar os elementos prototípicos da estrutura composicional da poesia de cordel, tendo em conta as seguintes considerações, dispostas nos Parâmetros curriculares nacionais: terceiro e quarto ciclos do ensino fundamental: língua portuguesa: 


\section{FACULDADE DE FoRMAÇÃo de PROFESSORES}

O tratamento do texto literário oral ou escrito envolve o exercício de reconhecimento de singularidades e propriedades que matizam um tipo particular de uso da linguagem. É possível afastar uma série de equívocos que costumam estar presentes na escola em relação aos textos literários, ou seja, tomá-los como pretexto para o tratamento de questões outras (valores morais, tópicos gramaticais) que não aquelas que contribuem para a formação de leitores capazes de reconhecer as sutilezas, as particularidades, os sentidos, a extensão e a profundidade das construções literárias (1998, p. 27).

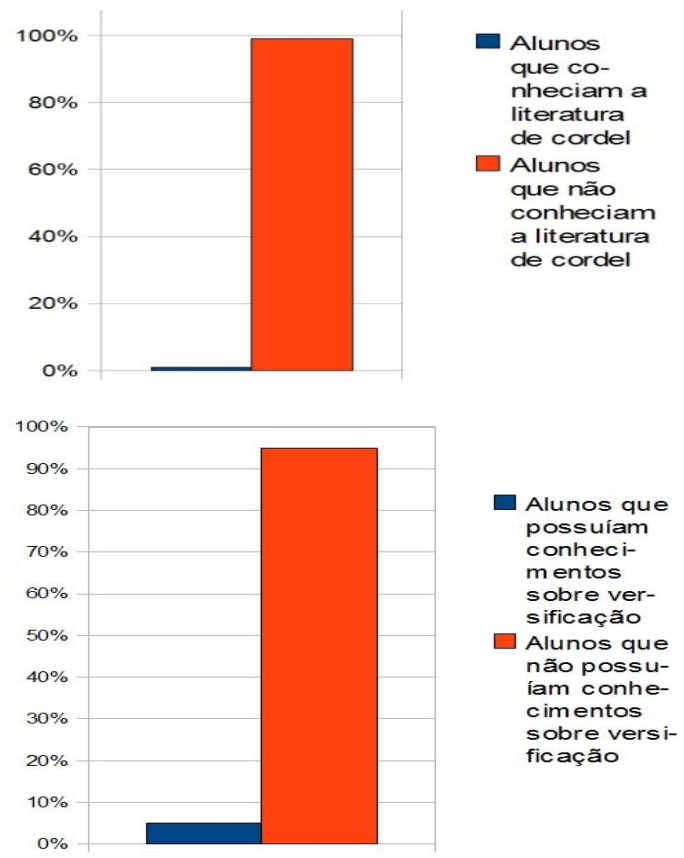

Também se considerou fundamental enxergar a poesia de cordel como parte integrante da diversidade cultural constitutiva do Brasil, como salientam os Parâmetros curriculares nacionais: terceiro e quarto ciclos: apresentação dos temas transversais, na seguinte passagem:

[...] o conhecimento dessa característica plural do Brasil é extremamente relevante. Ao permitir o conhecimento mútuo entre regiões, grupos e indivíduos, ele forma a criança, o adolescente e o jovem para a responsabilidade social de cidadão, consolidando o espírito democrático (1998, p. 123). 
A poesia de cordel deve ser, portanto, considerada e valorizada como objeto de ensino nas escolas. Embora frequentemente se anuncie isso, há a ocorrência de apenas uma indicação de trabalho com o gênero cordel, destinado à antiga $7^{\mathrm{a}}$ série, atual $8^{\circ}$ ano, na proposta de seriação do ensino fundamental, do documento de Reorientação curricular proposto pela Secretaria de Estado de Educação (2006). No artigo "O cordel como objeto de ensino", Maria Isaura Rodrigues Pinto aponta essa debilidade, ao afirmar que: "A quase ausência de folhetos nos livros didáticos e o tratamento, muitas vezes, equivocados do assunto quando consegue ser alcançado à condição de matéria de leitura e de aula provam que o cordel ainda não está efetivamente na pauta da educação formal” (2006, p. 21).

Outro aspecto considerado relevante, durante a implementação do projeto, foi a necessidade de que a aula tivesse uma abertura para que o aluno fosse instigado a expor suas ideias e pontos de vista - seja através da escrita ou oralmente -, como uma prática para a vida cotidiana e social. Assim, o aluno foi estimulado a dialogar com o outro ou com aquilo que lhe estava sendo passado como conteúdo e informação, usando (sabendo usar) as ferramentas certas para que a ação comunicativa fosse efetuada de forma clara e eficiente. Ou seja, sendo entendido e, ao mesmo tempo, fazendo-se entender.

\section{Resultados obtidos}

Durante o período de implementação do projeto, foram realizados onze encontros com a turma selecionada para aplicação das atividades. As estratégias desenvolvidas buscaram inserir o gênero cordel nas aulas de Língua Portuguesa. O projeto começou a ser posto em prática com a apresentação de músicas e curiosidades relacionadas à literatura de cordel. Também foram exibidas xilogravuras (ilustrações presentes nos folhetos), além da apresentação de uma leitura dramatizada feita pelo grupo Cordel em Cena, do folheto intitulado O Romance do Pavão Misterioso, de José Camelo de Melo Rezende. A finalidade era despertar o interesse dos alunos por esse tipo de produção literária. Essas atividades foram concluídas com sucesso, já que os alunos demonstraram grande interesse e atenção durante os comentários e a encenação do grupo. Dando continuidade às atividades, foi realizada uma leitura dinâmica em conjunto com a tur- 
ma. A atividade buscou incentivar, de forma lúdica, o gosto pela leitura da poesia de cordel, pois como diz Geraldi: "Importa que o aluno adquira o gosto de ler pelo prazer de ler, não em razão de cobranças escolares" (2006, p. 63).

No primeiro momento, a grande maioria dos alunos se mostrou desmotivada e resistente devido ao tamanho do texto a ser lido e estudado. Porém, no decorrer do processo, os alunos começaram a ter prazer em ler o diálogo entre os personagens, chegando a disputar quem seria qual personagem, sem que fossem necessárias intervenções e solicitações. Durante essas atividades, foram lembradas as seguintes palavras de Rubem Alves, presentes no texto "É como ouvir música": "É a experiência de ouvir que nos faz querer dominar a técnica da leitura para poder penetrar na emoção do texto".

O projeto prosseguiu voltando-se para o exame das especificidades do cordel, a fim de que os alunos fossem capazes de distinguir esse gênero discursivo de outros. Foram trabalhados, de maneira dinâmica, elementos de versificação, tais como: estrutura, conceitos de verso, estrofe, rima e ritmo. Para tanto, entre outros recursos, utilizou-se o quadro negro, onde foram afixados cartazes com palavras, que serviram de ponto de partida para a produção de rimas. Também, no quadro negro, foram dispostas algumas estrofes, sobre as quais foram formuladas perguntas acerca do número de versos e da composição das estrofes. Para exemplificarmos o conceito de ritmo, foi utilizado, em conjunto com a turma, o recurso das palmas, o que tornou a aula alegre e divertida.

Para demonstrar o processo da intertextualidade, foi usada a música de Ednardo, chamada Pavão Mysteriozo. Com tal recurso, foi possível demonstrar o quanto a literatura de cordel influencia a produção de outros textos e está representada em outros gêneros como a música, o filme e a peça teatral. Essa atividade despertou uma atenção maior dos alunos pelas características regionais nordestinas presentes na música.

Uma das propostas finais do projeto consistiu em solicitar aos alunos que elaborassem, em grupo ou individualmente, uma poesia de cordel, com o tema Copa do Mundo. A princípio, nem todos quiseram realizar a atividade, entretanto, após terem sido colocadas no quadro palavras vinculadas ao universo do futebol e da Copa do 
Mundo, como auxílio, eles começaram a escrever e produziam folhetos similares aos de cordel, incluindo ilustrações bem interessantes. O pleno envolvimento de todos na atividade só foi garantido, quando alguns alunos que já tinham dado início à tarefa começaram a ler em voz alta as rimas elaboradas, suscitando uma pequena disputada entre eles para ver quem produzia a rima mais engraçada e a poesia mais interessante e, consequentemente, o folheto mais significativo. Os alunos se sentiram orgulhosos ao verem, ao término das atividades, seus trabalhos expostos em varais, como igualmente ficaram os folhetos de cordel por eles estudados, durante o período de execução do projeto.

Curiosamente, mesmo sem que tivesse sido solicitada a confecção de folhetos em casa, um dos alunos ficou tão interessado por esse tipo de poesia que elaborou um cordel em casa e o apresentou na aula seguinte para a turma.

\section{Conclusão}

No livro Acorda cordel na sala de aula, um relato do poeta Manoel Monteiro feito a partir de suas experiências ao trabalhar com o cordel nas escolas, revela a importância dessa proposta e um dos objetivos almejados ao realizá-la: "o folheto sempre irá despertar interesse. O que a gente quer é "viciar" o aluno a gostar de ler. Se ele gosta de ler um folhetinho, depois lê um romance, dois, três... Até o dia em que vai enveredar por outras leituras. E, quem lê, sabe!" (2006, p. 29).

O ensino do cordel deve ser empolgante tal como um folheto, estimulando o gosto pela leitura. Para tanto, é válido atentar para o que é proposto por João Wanderley Geraldi, no texto "A leitura - fruição do texto", quando considera que hoje "se busca recuperar uma forma de interlocução praticamente ausente nas aulas de Língua Portuguesa: o ler por ler, gratuitamente" (2006, p. 97). O próprio Geraldi reitera esse pensamento ao dizer que: "É obvio que essa gratuidade tem boa paga: a informação disponível, como o saber, frequentemente gera outras vantagens" (2006, p. 98).

Por isso, além do propósito de apresentar o gênero cordel, o projeto em questão também almejou despertar no aluno o prazer pela 
leitura, incentivando-o a se tornar um leitor recorrente e reflexivo, capaz de extrair significados dos textos lidos.

\section{REFERÊNCIAS BIBLIOGRÁFICAS}

ALVES, Rubem. "É como ouvir música." Disponível em: <http://www.rubemalves.com.br/ecomoouvirmusica.htm>. Acesso em: 04 ago. 2010.

BRASIL. Parâmetros curriculares nacionais: terceiro e quarto ciclos do ensino fundamental: língua portuguesa. Secretaria de Educação Fundamental. Brasília: MEC/SEF, 1998.

BRASIL. Parâmetros curriculares nacionais: terceiro e quarto ciclos: apresentação dos temas transversais. Secretaria de Educação Fundamental. Brasília: MEC/SEF, 1998.

GERALDI, João Wanderley (Org.). O texto na sala de aula. São Paulo: Ática, 2006.

PINTO, Maria Isaura Rodrigues. "O cordel como objeto de ensino". In: Linguagem em (re)vista. Niterói: ano 3, nº 5, 2006.

REZENDE, José Camelo de Melo. O romance do pavão misterioso. Rio de Janeiro: Gonçalo Ferreira Stúdio Gráfico e Editora, 2000.

SECRETARIA de Estado de Educação. Livro I: Linguagens e códigos. Reorientação curricular. Rio de Janeiro, 2006.

VIANA, Arievaldo Lima (Org.). Acorda cordel na sala de aula. Fortaleza: Tupynanquim Editora / Queima Bucha, 2006. 